\title{
THE PSYCHIATRIST AS AN EXPERT WITNESS
}

\author{
Manfred S. Guttmacher, M.D.†
}

7 HE VOICE OF AMERICAN PSYCHIATRY is certain to be raised in praise of the decision in Durham v. United States. Psychia-

1 trists have impatiently, but hopefully, awaited such a pronouncement. In its excellently documented decision, the court pointed out that even before the $M^{\prime} N$ aghten rules were pronounced in 1843 , the great ninteenth-century American authority on legal psychiatry, $\mathrm{Dr}$. Isaac Ray, adversely criticized the criterion of responsibility based on an ability to distinguish between right and wrong. Ray's English contemporary, Dr. Henry Maudsley, declared, soon after the rules appeared, that the judges were holding to "an absurd dictum which has long been discredited by medical science." Through the years, these doughty critics have been followed by many of the leaders in psychiatry in this country and in Great Britain; such men as William White, Karl Menninger, Overholser, Alexander, Zilboorg, McNiven, and David Henderson have been openly critical of the rule. This author has recently participated in two polls of American psychiatric opinion on the adequacy of the M'Naghten formula in the light of modern psychiatric knowledge. In the polls of the American Psychiatric Association and of the Group for the Advancement of Psychiatry, the rules were overwhelmingly rejected.

Recently, the medical critics of the rules had become heartened by the statements of prominent American jurists. Mr. Justice Frankfurter in his testimony before the Royal Commission on Capital Punishment was forthright in his criticism of the rules, stating,

They are in large measure abandoned in practice, and therefore $I$ think the M'Naghten Rules are in large measure shams. That is a strong word, but $I$ think the M'Naghten Rules are very difficult for conscientious people and not difficult enough for people who say, "We'll just juggle them!"

In the dissenting opinion in Smith v. Baldi, ${ }^{1}$ Chief Judge Biggs of the United States Court of Appeals for the Third Circuit spoke out just as clearly against the century-old legal formula of responsibility of

† Chief Medical Officer, Supreme Bench, Baltimore, Md.

${ }^{1} 192$ F. 2 d 540 (C.A. 3d, 1951). 
the State of Pennsylvania. And now there comes this opinion of Judge Bazelon-the first official break-through in the line that has stubbornly resisted change, decade after decade.

The opinion presents adequately the major faults that modern psychiatry finds in the "knowledge" and the "irresistible impulse" tests. The chief criticisms of the rules in the May 1954 report on "Criminal Responsibility and Psychiatric Expert Testimony," formulated by the Committee on Psychiatry and Law of the Group for the Advancement of Psychiatry, can be summarized: (1) The courts do not deem it necessary to require psychiatrists to work within the narrow confines of such restrictive conceptions as the "knowledge" tests in determining an individual's fitness to stand trial, nor in advising the court in regard to his disposition after trial. (2) The rules touch only a fraction of the undeterrable mentally ill. (3) The rules put a false emphasis on intellect, reason, and common sense and underemphasize the emotional pressures that energize behavior. (4) Only in cases of mental disorder marked by disturbed consciousness and in cases of idiocy can the conscientious psychiatrist feel that he is replying honestly to questions based on the M'Naghten rules. (5) Psychiatry has no device to determine satisfactorily the capacity of the individual to distinguish right and wrong and appreciate the consequences of his acts.

Judge Bazelon's opinion expresses directly an important defect in the rules that is only implied in the above criticisms:

The fundamental objection to the right-wrong test, however, is not that criminal irresponsibility is made to rest upon an inadequate, invalid or indeterminable symptom or manifestation, but that it is made to rest upon any particular symptom. In attempting to define insanity in terms of a symptom, the courts have assumed an impossible role, not merely one for which they have no special competence. As the Royal Commission emphasizes, it is dangerous "To abstract particular mental faculties, and to lay it down that unless these particular faculties are destroyed or gravely impaired, an accused person, whatever the nature of his mental disease, . must be held to be criminally responsible. ..." In this field of law as in others, the fact finder should be free to consider all information advanced by relevant scientific disciplines. ${ }^{2}$

The opinion does not fully convey the difficulties and the dilemmas that have faced the psychiatrist, when he has tried to assist the court, hamstrung by the formula of criminal responsibility used in the courts of federal jurisdiction and in all of the state courts but those

$$
\text { 2P. } 872 .
$$


of New Hampshire. This, of course, is not said in criticism of the opinion because such a detailed discussion would hardly be appropriate. But things have reached the point that many thoughtful psychiatrists, who have had court experience, have become so impressed with the difficulties of rendering conscientious service to the courts under existing rules, and are so overwhelmed by the challenge of devising a substitute formula, satisfactory to both law and medicine, that they have become nihilists. If some constitutional method could be found to do away entirely with the defense of insanity and have psychiatric opinion used only in the determination of fitness to stand trial and in assisting in disposition after conviction, they would welcome it.

The new rule announced in the opinion is really the wise old rule of New Hampshire, which was originated by that admirable triumvirate of jurists, Justices Perley, Ladd, and Doe, with the assistance of Dr. Isaac Ray. The author has consulted psychiatrists who have testified in criminal cases in New Hampshire, in which pleas of insanity have been made. There, as elsewhere, such pleas are generally entered only in homicide cases and, to be sure, the good people of New Hampshire rarely indulge in murder. But the law was reported to work admirably in those few cases in which it has been used.

At the 1953 meeting of the American Psychiatric Association, the author presented a paper entitled, "The Quest for a Test of Criminal Responsibility." In it, he suggested five alternatives: doing away with the plea of insanity if possible; leaving the M'Naghten rules unchanged; adding the irresistible impulse to the M'Naghten formula; equating criminal irresponsibility with civil committability to a mental hospital; and adopting the New Hampshire rule. He then had the members of the audience vote on these five alternatives. The New Hampshire rule, the formula set forth in Judge Bazelon's opinion, was favored by nearly ninety per cent.

It is, of course, well to realize that although the rule announced in the opinion will be a vast improvement over the criteria of responsibility in common use, difficulties will still exist. No exact and flawless measurements of human behavior are obtainable. There will be uncertainty and differences of opinion as to what constitutes "a diseased or defective mental condition." And there will at times be doubt as to whether or not the act was the product of the existing mental abnormality. The so-called "borderline cases," the psychopaths and 
the severe character neurotics, will still prove to be the difficult cases under the new rule. For the time being, at least, many of them may be dealt with under special enactments. There is a marked trend today to place these borderline cases, who are not psychotic but who have nevertheless a seriously abnormal personality structure, in separate legal categories. This is illustrated by the rash of sexual psychopath statutes. Twenty states now have such laws, many of them of doubtful value. Another example of such a trend is the new Maryland Defective Delinquent Law which provides indeterminate sentences in a separate institution for intellectually and emotionally defective convicted defendants, who are considered to be clearly dangerous to society. Nearly all of these so-called "psychopath statutes" state that only individuals who are not insane come within their scope. It seems to this author probable that the new rule will be somewhat more liberally interpreted than the old ones and, in consequence, the group of the criminally insane will be somewhat broadened. If this will be the case, some of the more severe cases of character disorder (severe psychopaths and severe character neurotics) will doubtless be judged to belong in the group of insane. There is certain to be professional disagreement as to whether some of these cases should be classified as psychotic (schizophrenic) or psychopathic (schizoid psychopaths). The training and orientation of the psychiatrist is likely to be the decisive factor. If his orientation is psychoanalytic, he will be more likely to consider cases with severe character disorders as suffering from a mental disease.

With a new definition of insanity, it will be necessary to reconsider the criterion for recovery that permits the release of the criminally insane from the hospital. In the past this criterion has not been spelled out in most jurisdictions. In Maryland most judges have held that the knowledge-of-right-and-wrong test is the criterion, since the defendant had been committed under this test. But, we know that most inmates of institutions for the insane, if examined in regard to their knowledge of right and wrong, would pass the test perfectly. Otherwise, it would be impossible to have wards with a hundred inmates and one or two attendants, as is all too often the case in many of our state hospitals. It has always seemed to me that the chief criterion for civil committability, i.e., whether the patient is of danger to himself or others, should be the standard that determines the right of all committed psychiatric patients to be restrained in or released from the hospital, regardless of the source and type of commitment. 
Under the new rule this should certainly be the basis for decisions in regard to release. The mere presence or persistence of mental disease cannot be the criterion. Many patients who have been dangerous in the past, and may even have carried out a serious symptomatic anti-social act, have remissions of many years' duration, during which they are dangerless and can safely be at large in the community. Yet, in most instances the experienced psychiatrist can find remnants of the disorder and is clearly unable to testify that the patient no longer has a mental disease.

For the psychiatrist, the chief merit of the new rule is that it permits him to present his testimony in regard to the mental condition of the accused in concepts that are familiar to him and that actually exist in mental life. He will be thinking and talking as a medical psychologist, rather than as a theologian or a metaphysician.

The legal methods of presenting expert testimony do not fall within the scope of the opinion. However, to this author, it seems desirable in such a symposium to point out the fact that most psychiatrists who have had courtroom experience feel that they have been as greatly hampered from giving honest and effective assistance to the court by the methods and rules of legal procedure as they have been by working in the M'Naghten strait jacket. Doubtless, the adversary method of trial has proved through the centuries to be an effective way of presenting factual evidence, but it seems to this author a far less satisfactory method for the presentation of opinion testimony. This is particularly true in the field of psychiatry, where one is in large measure dealing with complex concepts and imponderable entities. The same criticism may be made in regard to the insistence on "yes or no" answers. Psychiatrists share the opposition of most other expert witnesses to the hypothetical question as a means of ascertaining truth. Psychiatrists are in general agreement that the only congenial way in which to appear as an expert witness in a criminal proceeding is as the neutral representative of the court. More than twenty per cent of psychiatrists, and among them are many of the ablest members of the profession, refuse all employment as a partisan witness.

There are, of course, several methods in use in various jurisdictions for the employment of nonpartisan experts. Today there is a rapidly developing system for the appointment of fully qualified medical experts to examine criminal defendants and plaintiffs in civil suits and file reports with the court. A pilot experiment of this type was 
begun in 1952 in the Supreme Court of New York County, in personal injury cases. The funds came from a joint grant by the Alfred P. Sloan Foundation and the Ford Motor Company Fund. Such a system has recently been devised by a joint committee of the Medical and Chirurgical Faculty and the Maryland State Bar Association for the courts of Baltimore, to be used in civil cases, and will soon be in effect. The medical society provides the courts with a list of three or four qualified experts in each specialty, and these men are called upon in rotation to advise the court. The cost is shared by the litigating parties. For thirty years, the criminal courts of Baltimore have had attached to them a psychiatric clinic. All defendants for whom the issue of insanity has been raised are examined and the report made available to the defense and the prosecution, as well as to the court. The right of either party to employ his own experts is, of course, preserved. But for more than a decade there has been no true "battle of experts" in a criminal case in Baltimore. The opinion of the court clinic staff, largely because of its nonpartisan status, has been so generally accepted by the court and the jury, that it has been found uneconomical and futile to attempt to refute it by employing partisan expert testimony.

It is also encouraging that the American Law Institute in drafting its New Model Criminal Code is seeking the advice of psychiatric consultants not only in regard to substantive matters but also in regard to procedural problems.

To this author, who has had a very limited experience in reading legal opinions, it is indeed encouraging to find in this opinion such a wide study of the technical medical literature and such a thorough understanding of it. It leaves one to hope that the shibboleth that the disciplines of law and medicine are antithetic may soon be abandoned. 